\title{
REGIME FISCAL, INVESTIMENTO EM PETRÓLEO E OPÇÕES REAIS.
}

\author{
Fernando Antonio Slaibe Postali ${ }^{*}+$
}

\begin{abstract}
Resumo
O objetivo deste artigo é avaliar o impacto dos benefícios governamentais da indústria do petróleo no Brasil - royalties e Participações Especiais - na decisão de investir no desenvolvimento de reservas de petróleo. Utilizamos a metodologia de opções reais, que considera o valor das flexibilidades gerenciais no projeto de investimento. O modelo admite a opção de esperar e a opção de abandonar, no qual se simula o impacto de diferentes estruturas de alíquotas de royalties e de Participações Especiais sobre as razões preço-custo que determinam o desenvolvimento da reserva ou a saída da indústria. A partir de um experimento de Monte Carlo, estima-se uma trajetória para o preço e para o custo operacional, com vistas a avaliar as receitas esperadas para o governo sob cada estrutura de alíquotas. Os resultados sugerem que as Participações Especiais, apesar de seu potencial arrecadatório maior, podem retrair a decisão de investir tanto quanto (ou mesmo mais que) os royalties. Desta forma, a ampliação desta modalidade tributária, cuja discussão foi motivada pelas recém anunciadas descobertas do pré-sal, pode não ser uma boa iniciativa.
\end{abstract}

\begin{abstract}
The aim of this paper is to evaluate the impact of the Brazilian petroleum fiscal regime - royalties and special participation tax - on the decision to invest in the development of oil and gas reserves in Brazil. We use the Real Option approach, which considers the value of managerial flexibilities. The model admits the option to wait and the option to abandon. It is simulated the impact of different royalties and special participation tax rates on the threshold price-cost ratios to develop the reserve and to exit the industry. Through a Monte Carlo experiment, it is also estimated a path for both prices and costs with the purpose of assessing the expected revenues to the government under each tax rate. Results suggest that special participation tax, despite its ability to increase revenues, is able to distort the decision to invest as much as (or even more than) royalties, which shows that extending this modality of tax, whose discussion was motivated by the just announced pre-salt discoveries, may not be a good initiative.
\end{abstract}

\footnotetext{
*Universidade de São Paulo, Faculdade de Economia Administração e Contabilidade, Departamento de Economia.

${ }^{\dagger} \mathrm{O}$ autor agradece os comentários de Paulo Picchetti, Gerson Francisco, Edmilson dos Santos, Francisco Anuatti Neto, Luiz Brandão e de dois pareceristas anônimos. Eventuais erros são de responsabilidade do autor.
} 


\section{Introdução}

A grande maioria dos países produtores de petróleo estabelece um sistema fiscal especial sobre a produção de óleo e gás, com o objetivo de aumentar a parcela do governo sobre a renda da atividade. Embora a incerteza seja inerente a qualquer decisão de investimento, o risco exploratório representa uma peculiaridade adicional da indústria do petróleo. Assim, o desenho do regime fiscal tem impactos significativos sobre a percepção de risco (Mayo, 1979; Fraser, 1993) e, consequentemente, sobre a decisão de investir. Por outro lado, a análise convencional de investimentos, baseada no valor presente líquido, ignora o valor da flexibilidade gerencial do projeto (Kulatilaka, 1995; Laughton, 1998), de modo que o impacto do sistema fiscal sobre a decisão de investir em desenvolvimento de jazidas pode ser diferente do previsto pela abordagem tradicional, mesmo que o agente seja neutro ao risco.

Em novembro de 2007, a Petrobras anunciou a existência de um gigantesco campo de recursos hidrocarbonetos - o Campo de Tupi - com reservas estimadas entre 5 e 8 bilhões de barris ${ }^{1}$. O anúncio representa um importante marco na indústria do petróleo, já que inaugura uma nova fronteira de exploração na camada pré-sal, com resultados muito promissores, segundo as primeiras avaliações. Qualquer que seja o volume de recursos recuperáveis, a nova fronteira pode resultar em um grande redesenho das reservas brasileiras, podendo aumentá-las em até $40 \%$ e elevar o Brasil à condição de grande produtor. Ainda que grandes incertezas geológicas precisem ser dissipadas no tocante à viabilidade de sua produção em condições inóspitas, o governo lançou propostas preliminares de alterar o regime tributário dos novos campos à luz das suas novas condições de lucratividade e risco. Uma das ideias seria aumentar as Participações Especiais na tributação, com o intuito de apropriar uma fatia maior da renda do recurso.

O objetivo deste artigo é avaliar o impacto deste regime fiscal específico incidente na extração de petróleo - chamados Benefícios Governamentais sobre a decisão de investir no desenvolvimento de reservas, através de uma aplicação de Postali e Picchetti (2006). Consideram-se duas flexibilidades gerenciais no projeto de investimento: a opção de adiar o desenvolvimento da reserva e a opção de encerrar a produção. A metodologia, baseada na abordagem de Opções Reais (Dixit e Pindyck 1994), consiste em simular o impacto de algumas combinações de alíquotas de royalties e de Participações Especiais na razão preço-custo crítica que induz a decisão de investir ou de sair. A análise de opções reais representa uma poderosa ferramenta que incorpora o valor de flexibilidades gerenciais no projeto de investimento.

O trabalho contém mais cinco seções, além desta introdução geral: na seção 2, apresenta-se um panorama sobre opções reais, assim como um resumo das principais contribuições acerca da neutralidade tributária em recursos não-renováveis; a seção 3 descreve o sistema de benefícios governamentais do petróleo no Brasil; a seção 4 apresenta um modelo de investimentos em opções reais para apoiar as simulações e comenta os resultados e a seção 5 traz as considerações conclusivas. Os resultados mostram que uma combinação intermediária de alíquotas causa um impacto menor na decisão de investimento do que uma alíquota única de $10 \%$ ad valorem, conforme se pratica na grande

\footnotetext{
${ }^{1}$ Fonte: Petrobras. Comunicado de Fato Relevante de 8/11/2007. http: //www2.petrobras. com.br/ri/spic/bco_arq/FR-AreaTupi-Port.pdf.
} 
maioria dos projetos de extração no Brasil. No entanto, quando se incorporam as flexibilidades gerenciais a partir de uma análise de opções reais, a ampliação das Participações Especiais pode resultar em efeitos deletérios sobre a decisão de investir, de modo que as discussões sobre sua ampliação na fronteira do pré-sal devem ser conduzidas com cautela, a fim de se evitar uma retração de investimentos.

\section{A abordagem de Opções Reais e a tributação de rendas minerais}

A análise convencional de investimentos é baseada no conceito de Valor Presente Líquido (VPL), o qual é definido pela diferença entre o valor atual dos fluxos de caixa gerados pelo projeto e o custo do investimento inicial. Tratase de encontrar uma regra de decisão objetiva quanto a investir ou não em um determinado projeto. De acordo com esta análise, o investimento deve ser aceito sempre que $V P L>0$; investimentos com VPL negativo devem ser descartados.

Segundo Dixit e Pindyck (1994), apesar da facilidade operacional, a avaliação tradicional por Valor Presente Líquido apresenta três deficiências fundamentais: i) não incorpora a incerteza de forma satisfatória, limitando-se a um prêmio de risco sobre a taxa de desconto; ii) não avalia o custo de oportunidade do investimento, decorrente de sua irreversibilidade e iii) não incorpora o valor de diversas flexibilidades admitidas por um projeto de investimento, sobretudo a possibilidade de adiamento da tomada de decisão. Na realidade, o agente dispõe de certa margem para alterar o timing de uma sequência de decisões irreversíveis e esta flexibilidade gera valor, o qual não pode ser medido sob uma análise de VPL ${ }^{2}$. Assim, um investimento com valor presente líquido negativo não deve ser necessariamente descartado, já que o agente tem a opção de esperar pela chegada de informações adicionais antes de tomar a decisão irreversível.

As deficiências do VPL contribuíram para o desenvolvimento da abordagem das Opções Reais, uma ferramenta útil que propicia um tratamento mais apropriado para os gastos irreversíveis, para a incerteza e para as flexibilidades sobre a decisão de investir. Trata-se de interpretar o investimento como uma opção americana de compra cujo ativo subjacente é o valor do projeto e o preço de exercício é o gasto com o investimento. Tomar a decisão de investir significa "exercer a opção de compra", sendo, por consequência, irreversível.

A literatura de opções reais cresceu fortemente nos últimos 20 anos, através da incorporação gradativa de diversas opções estilizadas em contribuições seminais, como opção de fechamento (McDonald e Siegel 1985), de expansão da capacidade (Pindyck 1988), de investir (Paddock et al. 1988, Abel et al. 1996), de abandonar (Myers e Majd 1990). A ferramenta das opções reais se expandiu em direção a aplicações nas mais diversas áreas (Schwartz e orgs.) como poluição, desenvolvimento de terras, investimentos em estoques, criação de infraestrutura, energia elétrica, dentre outros.

\footnotetext{
${ }^{2}$ Isso não significa que o VPL seja um critério rígido. À medida que novas informações são incorporadas, ele pode ser atualizado, para cima ou para baixo. A vantagem das opções reais é que elas permitem avaliar como as informações afetam as flexibilidades gerenciais, quando elas existem.
} 
A literatura sobre tributação de recursos não-renováveis também está consolidada. Conforme Garnaut e Ross (1983) argumentam, o setor extrativo possui peculiaridades relativas à incerteza exploratória, de modo que a carga fiscal tende a afetar o volume de investimentos na medida em que produz impactos na percepção de risco. Os trabalhos nesta área sempre procuraram identificar o regime fiscal ótimo no sentido de minimizar a distorção sobre a decisão de investir ${ }^{3}$.

De acordo com Blake e Roberts (2006), as relações entre os poderes concedentes e os concessionários no setor de petróleo ao redor do mundo podem ser classificadas em três categorias gerais, de acordo com o procedimento de coleta de renda pelo governo, assim como regime de propriedade sobre os recursos:

1. Sistemas Tributários puros $^{4}$ : consiste na coleta da renda mineral a partir de impostos, que compreendem algumas regras específicas (deduções, preço de referência, etc.) para a determinação da renda a ser tributada; neste regime, o direito de propriedade sobre os recursos extraídos é transferido para o concessionário, que pode dispor livremente deles para fins comerciais, enquanto o governo recolhe sua parcela na renda através de impostos (royalties, imposto de renda, etc).

2. Sistemas de Contrato: nesta modalidade, o poder concedente não abre mão dos direitos de propriedade sobre o recurso extraído, mas contrata empresas privadas para gerir as atividades de produção. Existem dois exemplos típicos de sistemas contratuais: os Contratos de Partilha, no qual o governo e o concessionário repartem entre si o recurso produzido, segundo critérios pré-definidos em contrato; e os Acordos de Serviço, no qual o concessionário recebe uma remuneração em troca da gestão da produção.

3. Taxa de Retorno: trata-se de uma espécie de regime tributário que poderia ser classificada como sistema tributário puro (a), mas que possui uma especificidade importante: o poder concedente assume todo o risco da atividade, garantindo uma taxa de retorno para o concessionário. Consiste em acumular todos os gastos previstos e imprevistos a uma taxa de retorno permitida por lei, com vistas a deduzi-los da receita da atividade para compor a base de arrecadação. Este sistema tributário raramente é aplicado na prática, devido à complexidade das informações requeridas para sua implementação, introduzindo problemas de agência na relação contratual. Um exemplo desta categoria fiscal é o Imposto de Brown (1948). Na prática, variantes desta modalidade são mescladas com sistemas tributários puros ou com sistemas contratuais, já que os direitos de propriedade podem ser designados tanto ao concessionário quanto ao poder concedente.

A partir da análise tradicional de valor presente líquido, a literatura sobre a tributação de recursos minerais [e.g.: Mayo (1979); Campbell e Lindner(1985a, 1985b), Fraser (1993), Zhang (1997), Fraser (1998)] converge na

\footnotetext{
${ }^{3}$ Vale ressaltar que os tributos podem afetar qualquer decisão de investir. A incerteza exploratória apenas torna esta discussão mais sensível no setor mineral/recursos não-renováveis. Além disso, como o petróleo é um recurso energético de caráter estratégico, a discussão sobre o efeito do regime fiscal sobre o setor é de grande relevância.

4 Taxes Royalty.
} 
conclusão de que uma estrutura tributária baseada em uma alíquota sobre a receita (royalty) gera uma distorção mais forte sobre a decisão de investir do que um imposto sobre a renda do recurso - incidente sobre a receita bruta descontada de todos os custos. A distorção decorre, fundamentalmente, do fato de que um imposto sobre faturamento transfere grande parte do risco da atividade para a empresa, ao passo que um imposto sobre a renda permite uma divisão mais equilibrada destes riscos. Além disso, um imposto sobre a renda tem um impacto menor no valor do investimento, pois não afeta sinal do seu valor presente líquido esperado, enquanto a tributação do faturamento pode inviabilizar um projeto antes lucrativo pela inversão do sinal do seu valor presente líquido esperado. Em sua forma ideal, - imposto de Brown ${ }^{5}$ - não há qualquer distorção sobre o investimento. Todavia, apesar de sua atratividade teórica, o imposto de Brown não possui aplicabilidade prática.

Sob o critério do VPL, avalia-se a neutralidade de um regime fiscal de acordo com sua capacidade de afetar alguma dimensão do investimento. Conforme sugerem Blake e Roberts (2006, p. 96), uma descrição intuitiva de um imposto neutro é aquele que mantém a ordenação de atratividade dos candidatos a investimentos com ou sem a tributação. No entanto, quando a interação entre gastos irreversíveis e flexibilidade é incorporada, um imposto neutro sob a abordagem do VPL pode apresentar efeitos adicionais sobre a decisão de investir, tendo em vista as não linearidades introduzidas na avaliação.

Existem trabalhos que incorporam o efeito da incerteza na avaliação da neutralidade tributária. Utilizando a abordagem da árvore de informações, Bradley (1998) simula como o valor de um projeto de extração de gás é afetado por diferentes estruturas tributárias que apresentam diferentes graus de não-linearidade, concluindo que o valor do projeto é altamente sensível à estrutura fiscal; Lund (1992) parte da abordagem do ativo replicante (Contingent Claim Analysis) para avaliar as distorções provocadas pelo regime fiscal petroleiro na Noruega, concluindo que este sistema apresenta impactos deletérios significativos na decisão de investir. Na mesma linha, Blake e Roberts (2006) incorporam a incerteza assumindo que o preço do petróleo segue um Movimento Browniano Geométrico (MBG), a fim de analisar o impacto de cinco regimes fiscais de diferentes países sobre o valor de um projeto. A distorção é medida por um índice que reflete o desvio no valor devido ao imposto e conclui-se que sistemas baseados na partilha de produção (Tanzânia e Trinidad e Tobago) são mais distorcivos do que sistemas baseados em impostos.

$\mathrm{Na}$ linha desta discussão, o objetivo deste artigo é avaliar os impactos de possíveis estruturas fiscais, em termos de combinações de alíquotas, sobre a atração de investimentos em petróleo no Brasil. Antes disso, a seção a seguir descreve sucintamente o sistema de benefícios governamentais sobre a produção de petróleo e gás natural no Brasil.

\footnotetext{
${ }^{5}$ Ver Brown (1948) e Mayo (1979). O Imposto de Brown é o exemplo extremo de modalidade de Taxa de Retorno. Ele estabelece a aplicação de uma alíquota sobre o valor da renda do recurso em cada um dos instantes de tempo, ou seja, sobre a parcela da receita acima dos custos totais. Desta forma, em períodos de renda líquida negativa, o tributo se torna um subsídio, de modo que o governo assume a totalidade do risco, determinando a neutralidade deste imposto. Como observa Mayo (1979), o imposto de Brown diminui o risco da firma investidora na medida em que reduz tanto o ganho quanto a perda na mesma proporção, ou seja, o desvio padrão dos resultados esperados torna-se menor. Para uma discussão, ver Postali (2002).
} 


\section{Benefícios Governamentais no Brasil}

Com vistas a evitar ineficiências de common pool, o Brasil estabelece em sua Constituição ${ }^{6}$ que todos os recursos minerais no subsolo terrestre e na plataforma continental pertencem ao público, que, por conseguinte, possui o direito de usufruir suas rendas. Portanto, como legítima proprietária, a União deseja converter a renda mineral em investimentos públicos, a fim de evitar a queda do bem estar das gerações futuras.

Esta é a principal racionalidade para a introdução de um regime fiscal especial sobre a produção de petróleo e gás, isto é, o governo está interessado em se apropriar da renda devido a seus direitos de propriedade. No entanto, conforme os argumentos acima apontados, o investimento neste setor é particularmente sensível à carga fiscal, já que esta afeta a distribuição de riscos entre governo e empresas.

O artigo $45^{\circ}$ da Lei do Petróleo ( ${ }^{\circ}$ 9478/97) prevê quatro modalidades básicas, incidentes basicamente sobre a produção: i) Bônus de Assinatura; ii) Royalties; iii) Participações Especiais e iv) Taxa de Ocupação e Retenção da área. Os itens ii e iv são obrigatórios em todos os contratos de concessão. Os detalhes de cada mecanismo, em especial das Participações Especiais, estão regulamentados no decreto 2705 de 3/08/98.

O bônus de assinatura corresponde ao montante ofertado pelo vencedor no leilão para obtenção da concessão, cujo valor não pode ser inferior ao mínimo fixado pela ANP no edital de licitação. Deve ser pago integralmente, em parcela única, no ato de assinatura do contrato ${ }^{7}$.

Os royalties constituem uma compensação financeira mensal à União incidente sobre o valor total da produção de óleo e gás. Em geral, a alíquota deste tributo é de $10 \%$ sobre o valor da produção, avaliada de acordo com um preço de referência calculado com base em uma cesta de tipos internacionais de petróleo ou gás. A ANP pode estabelecer em edital de licitação a redução, em até 5 pontos percentuais, da alíquota deste tributo, se julgar que as condições de produção e os riscos geológicos justifiquem tal medida. Os recursos arrecadados via royalties são divididos entre os Estados e os Municípios produtores, o Tesouro Nacional e os Ministérios da Ciência e Tecnologia e da Marinha.

As Participações Especiais caracterizam-se por compensações extraordinárias ao Governo resultantes de casos de grande volume de produção ou de grande rentabilidade ${ }^{8}$, com relação a cada campo de uma área de concessão. Este imposto incide apenas quando a produção atinge grandes volumes, cujos patamares dependem da profundidade do campo e da localização da lavra, de forma que um projeto de tamanho médio está isento ${ }^{9}$. A apuração deste imposto é feita pela aplicação de alíquotas progressivas sobre a receita líquida da produção trimestral de cada campo, isto é, a receita bruta menos os royal-

\footnotetext{
${ }^{6}$ C.F. Art. $20^{\circ}$, incisos V e IX.

7 O lance vencedor do leilão de concessão é só um dos critérios para a definição do consórcio vitorioso na licitação. Os outros critérios estão associados à capacidade técnica e financeira, a compromissos de compra de fornecedores nacionais e ao plano proposto de investimentos.

${ }^{8}$ Embora a lei do Petróleo defina a rentabilidade como critério de apuração, na prática, o fato gerador das participações especiais é o volume de produção. Devido à heterogeneidade dos campos, é possível que campos sem lucratividade, mas com volumes razoáveis de produção sejam obrigados a recolher participação especial ao governo, o que caracteriza uma potencial ineficiência.

9 As regras de apuração são complicadas e dependem de diversos fatores, como a profundidade e a localização (mar ou terra). Os detalhes estão no Decreto 2705/1998.
} 
ties, os investimentos exploratórios, os custos operacionais, a depreciação e os tributos legais. Tais alíquotas dependem da localização da lavra, do número de anos da produção e do respectivo volume trimestral de produção fiscalizada e variam entre $0 \%$ e $40 \%$. O objetivo principal da participação especial é permitir ao Governo obter uma parcela maior de renda dos projetos mais lucrativos. Existem seis faixas de tributação para este tipo de imposto: isenção, $10 \%, 20 \%, 30 \%, 35 \%$ e $40 \%$ da receita líquida trimestral ${ }^{10}$. Os recursos provenientes das Participações Especiais devem ser distribuídos entre os Estados e os Municípios produtores e os Ministérios das Minas e Energia e do Meio Ambiente.

Por fim, a Lei do Petróleo e o decreto 2705/98 preveem uma quarta modalidade de participação do governo nos benefícios da atividade petrolífera: o pagamento de uma taxa de ocupação ou retenção de áreas, cujo valor é determinado no contrato de concessão e deve ser recolhido no início de cada ano. Trata-se, de um modo geral, de um aluguel pela área explorada.

Das modalidades de benefícios governamentais, as mais importantes são os royalties e as Participações Especiais, tendo em vista que seus resultados são condicionados à produção. $\mathrm{O}$ bônus de assinatura, embora com potencial de inviabilizar investimentos (Postali 2002), não será objeto de estudo neste trabalho ${ }^{11}$.

Embora a Constituição brasileira defina a União como proprietária dos recursos do subsolo, a Lei do Petróleo estabelece que o petróleo extraído é de propriedade do concessionário, cabendo ao governo abocanhar sua fatia na renda a partir do regime fiscal específico composto destas quatro modalidades. Na taxonomia da Blake e Roberts (2006) descrita acima, todo regime brasileiro, em seus quatro tipos de tributo, pode ser caracterizado como um sistema tributário puro, tendo em vista que o direito de propriedade do recurso extraído recai sobre o produtor, que pode dispor livremente do petróleo produzido. Além disso, não há garantia de taxa de retorno e o concessionário assume boa parcela do risco do empreendimento ${ }^{12}$.

Recentemente, a partir do anúncio da descoberta do Campo de Tupi e a abertura da fronteira do pré-sal, com potencial de lucratividade considerável, o governo iniciou discussões no sentido de alterar a Lei do Petróleo para permitir uma mudança no sistema de benefícios governamentais, com vistas

\footnotetext{
10 Em termos gerais, estão sujeitos à Participação Especial os campos em terra com produção acima de 10 mil barris diários; campos no mar com produção acima de 20 mil barris dia, aumentando para 30 mil em poços mais profundos (acima de $400 \mathrm{~m}$ ). Quanto mais inóspito o local de produção, mais difícil a extração e, conseqüentemente, maior o limite de isenção; em segundo lugar, conforme o tempo vai passando, o limite de isenção se reduz. Além disso, a agência reguladora oferece uma faixa maior de isenção nos anos iniciais para que o investidor consiga diluir os gastos exploratórios realizados anteriormente à fase de produção. Se em um determinado trimestre a receita líquida de um campo for negativa, ela poderá ser compensada no cálculo da participação especial devida no mesmo campo nos trimestres subsequentes.

11 Deve-se ter em vista que o bônus de assinatura nem sequer é obrigatório no contrato de concessão, podendo ser substituído por outros critérios de seleção de concessionário, como a proposição de um programa mínimo de investimentos.

12 A distinção é mais importante do ponto de vista conceitual (em termos de direitos de propriedade) do que prático. As jazidas do pré-sal trouxeram a tona discussões sobre mudanças na legislação com vistas a instituir um sistema contratual baseado na partilha dos recursos extraídos. Entretanto, do ponto de vista contábil, faz pouca diferença para o concessionário entregar ao governo $10 \%$ da produção física de petróleo ou $10 \%$ do valor da produção, em royalties. As mudanças, aparentemente, visam fortalecer a posição do governo como detentor da propriedade dos recursos extraídos das mega-jazidas do pré-sal e, do ponto de vista prático, apenas acarretaria enormes custos de logística.
} 
a extrair maior parcela de renda. Uma das ideias, proposta pela ANP, seria a alteração do decreto $n^{\circ} 2705 / 98$, que estabelece normas para a cobrança das Participações Especiais, a fim de estendê-las para os futuros campos a serem concedidos.

A fim de se avaliar as consequências de uma possível extensão de uma modalidade similar às Participações Especiais sobre todos os projetos de investimento, a seção a seguir apresenta um modelo de tomada de decisões no qual são incorporadas duas flexibilidades gerenciais: a opção de investimento e a opção de saída.

\section{O modelo}

O modelo proposto é uma extensão modificada de Postali e Picchetti (2006), com a incorporação do efeito do tempo sobre o valor unitário da jazida a partir da estratégia de Brennan e Schwartz (1985). Do ponto de vista das etapas contratuais, o modelo se situa entre o fim da exploração (quando toda a incerteza de ordem geológica foi dissipada) e a declaração de comercialidade ${ }^{13}$, quando o concessionário deve decidir se desenvolve ou não o campo concedido. Assim como em Dixit (1989), assume-se que, uma vez em operação, a firma avalia a opção de encerrar a produção caso as condições econômicas sejam desfavoráveis.

Na nomenclatura de opções reais, pois, têm-se dois cenários possíveis para os concessionários empreenderem decisões irreversíveis: a) opção de converter jazida não-desenvolvida em jazida desenvolvida e b) opção de converter jazida em operação em jazida desativada.

Seguindo Postali e Picchetti (2006), assume-se que o preço $(P)$ e o custo operacional de produção $(C)$ sejam as variáveis de estado das quais o valor unitário da reserva desenvolvida dependa, tal que $V(P, C, t)$. Assim como em Costa Lima e Suslick (2006), assume-se que estas variáveis seguem um Movimento Browniano Geométrico (MBG):

$$
\begin{aligned}
& d P=\alpha P d t+\sigma_{P} P d Z_{P} \\
& d C=\phi C d t+\sigma_{C} C d Z_{C}
\end{aligned}
$$

onde $\alpha$ e $\phi$ são os crescimentos esperados do preço e do custo; $d Z_{P}$ e $d Z_{C}$ são processos de Wiener tal que $E\left(d Z_{P} d Z_{c}\right)=\rho d t, E\left(d Z_{P}\right)=E\left(d Z_{C}\right)=0$, $E\left(d Z_{P}\right)^{2}=E\left(d Z_{C}\right)^{2}=d t$, onde rho é o coeficiente de correlação entre as variações de $P$ e $C, \sigma_{P}$ e $\sigma_{C}$ são os desvios padrão instantâneos de cada processo.

O parâmetro $\phi$ é a taxa de crescimento esperada do custo operacional unitário. Ela também pode ser entendida como a taxa de decaimento do estoque físico do recurso, sob a hipótese de que este é inversamente proporcional ao custo unitário de extração ${ }^{14}$. Na medida em que a reserva decresce, o custo

\footnotetext{
${ }^{13}$ Ignora-se o time to build, isto é, assume-se que o desenvolvimento se conclui imediatamente após a declaração de comercialidade. Segundo Majd e Pindyck (1987), o relaxamento desta hipótese não traz diferenças qualitativas nos resultados, acentuando apenas o efeito da incerteza. Martins e Silva (2005) constroem um modelo que incorpora investimento incerto, seqüencial e com time to build, e concluem que a incorporação destes elementos pode gerar situações nas quais o aumento da incerteza pode antecipar a decisão de investimento.

14 Se S é o estoque e $C_{0} S_{0}=S_{t} C_{t}$, então $C_{t}=C_{0} e^{\phi t}$, o que implica em $S_{t}=S_{0} e^{-\phi t}$. Ver Postali e Picchetti (2006) para mais detalhes. Para as propriedades dinâmicas da função custo na extração de recursos não renováveis, ver Osmundsen (1998).
} 
unitário de extração tende a crescer, devido à redução na pressão dos poços (efeito Jevons).

Diferentemente de Blake e Roberts (2006), derivamos a equação que governa o valor unitário da reserva através de programação dinâmica (como em Martins e Silva 2005). A desvantagem desta abordagem é a necessidade de assumir uma taxa de desconto exógena na função objetivo, enquanto sob uma análise de ativo replicante, uma taxa de desconto ajustada ao risco pode ser derivada a partir das condições de equilíbrio no mercado de capitais (e.g.: CAPM). Por outro lado, sob programação dinâmica, a presença de um ativo replicante é desnecessária (Dixit e Pindyck 1994, p. 121).

O objetivo do investidor é maximizar o valor unitário da reserva e os lucros provenientes do recurso. Pelo Princípio de Bellman e assumindo neutralidade ao risco, tem-se:

$$
r V(P, C, t) d t=\Pi(P, C, t) d t+E_{0}(d V)
$$

A equação (3) estabelece a condição de ótimo do problema, que requer que o retorno da reserva à taxa livre de risco $^{15}, r V d t$, deve ser o igual aos lucros proporcionados pela jazida, $\Pi$, mais a variação esperada em seu valor, em equilíbrio. Em outros termos, o retorno total deve ser igual aos ganhos de capital somados aos dividendos.

A função lucro unitário é dada por:

$$
\Pi(P, C)=(1-R)(1-Y)[(1-\tau) P-C]
$$

onde $\tau$ é a alíquota de royalties, que incide sobre a receita, $Y$ é a alíquota média ${ }^{16}$ que engloba os tributos legais $I R P J+C S L L$ e $R$ é a alíquota de uma versão simplificada das Participações Especiais, que pode ser entendida como uma espécie de imposto de renda especial.

Pelo Lema de Itô, e desconsiderando ordens de $d t$ iguais ou superiores a 2 :

$$
d V=V_{P} d P+V_{C} d C+\frac{1}{2} V_{P P}(d P)^{2}+\frac{1}{2} V_{C C}(d C)^{2}+V_{P C} d P d C+V_{t} d t
$$

Como $Z$ é um processo de Wiener, $E\left(d Z_{P}\right)=E\left(d Z_{C}\right)=0, E\left(d Z_{P}\right)^{2}=E\left(d Z_{C}\right)^{2}=$ $d t$ e $E\left(d Z_{P} d Z_{C}\right)=\rho d t$. Portanto ${ }^{17}$ :

$$
\begin{aligned}
E_{0}(d V)=V_{P} P \alpha d t+V_{C} C \phi d t+ & \frac{1}{2} V_{P P} \sigma_{P}^{2} P^{2} d t+ \\
& +\frac{1}{2} V_{C C} \sigma_{C}^{2} C^{2} d t+V_{P C} \sigma_{P} \sigma_{C} P C d t+V_{t} d t
\end{aligned}
$$

Substituindo (6) em (3) e rearranjando:

\footnotetext{
15 Conforme salienta Pindyck (1988), os resultados do efeito da incerteza sobre a decisão de investir prescindem de qualquer hipótese sobre as preferências do agente em relação ao risco ou sobre em que medida o risco do projeto é correlacionado com o portfólio de mercado. Sejam as firmas neutras ou avessas ao risco, alterações estocásticas em $P$ (ou $C$ ) podem ser completamente diversificáveis e o efeito da incerteza sobre a regra de investimento será sempre o mesmo, podendo diferir apenas na intensidade.

16 Trabalhou-se com alíquota média pois, na prática, os tributos são não-lineares.

17 Notação: $V_{K}=d V / d K$ and $V_{K K}=d^{2} V / d K^{2}$.
} 


$$
\begin{aligned}
\frac{1}{2} V_{P P} \sigma_{P}^{2} P^{2}+\frac{1}{2} V_{C C} \sigma_{C}^{2} C^{2}+V_{P C} \sigma_{P} \sigma_{C} P C+V_{P} \alpha P+ \\
\quad+V_{C} \phi C+V_{t}+(1-R)(1-Y)[(1-\tau) P-C]-r V=0
\end{aligned}
$$

A expressão (7) é uma equação diferencial parcial sem solução analítica, devido ao termo $V t$, que expressa a variação no valor unitário da reserva conforme o tempo passa. Seguindo Brennan e Schwartz (1985), é possível trabalhar em termos reais, deflacionando o valor da reserva tal que $V(P, C, t)=$ $\tilde{V}(P, C) e^{-\pi t}$, onde $\pi$ pode ser entendida como a taxa de inflação. Pela definição, tem-se que $V_{t}=\pi \tilde{V}$. Substituindo em (7), encontra-se:

$$
\begin{aligned}
\frac{1}{2} \tilde{V}_{P P} \sigma_{P}^{2} P^{2}+\frac{1}{2} \tilde{V}_{C C} \sigma_{C}^{2} C^{2}+\tilde{V}_{P C} \sigma_{P} \sigma_{C} P C+\tilde{V}_{P} \alpha P+\tilde{V}_{C} \phi C+ \\
+(1-R)(1-Y)[(1-\tau) P-C]-(r-\pi) \tilde{V}=0
\end{aligned}
$$

Na qual $r-\pi$ é a taxa real de juros. Além disso, o MBG permite uma simplificação adicional: é possível reduzir a dimensão do problema e reduzi-la a uma única variável de estado, já que $V$ é uma função homogênea. Definindo $x=P / C$, tem-se $\tilde{V}(P, C)=C v(P / C)=C v(x)$ e o problema se reduz a encontrar $v(x)$.

As relações entre $\tilde{V}(P, C)$ e $v(x)$ acima definidas geram as seguintes expressões ${ }^{18}$ :

$$
\begin{gathered}
\tilde{V}_{P}=v^{\prime}(x) \\
\tilde{V}_{C}=v(x)-p v^{\prime}(x) \\
\tilde{V}_{P P}=v^{\prime \prime}(x) / C \\
\tilde{V}_{P C}=-x v^{\prime \prime}(x) / C \\
\tilde{V}_{C C}=x^{2} v^{\prime \prime}(x) / C
\end{gathered}
$$

Substituindo as relações acima em (7) e dividindo-se ambos os lados por C, tem-se ${ }^{19}$ :

$$
\begin{aligned}
\frac{1}{2}\left(\sigma_{P}^{2}-2 \rho \sigma_{P} \sigma_{C}+\sigma_{C}^{2}\right) p^{2} v^{\prime \prime}(x)+(\alpha-\phi) p v^{\prime}(x)-(r-\pi) v(x)+ \\
+(1-R)(1-Y)[(1-\tau) x-1]=0
\end{aligned}
$$

\footnotetext{
18 As notações $v^{\prime}(\cdot)$ and $v^{\prime \prime}(\cdot)$ indicam, respectivamente, primeira e segunda derivada com relação a $x$.

${ }^{19}$ A propriedade de homogeneidade é válida apenas quando ambas as variáveis seguem um MBG. Não é possível empreender a mesma transformação quando pelo menos uma das variáveis segue um processo de reversão à media (Ornstein-Uhlenbeck), já que o drift depende do nível da variável de estado. Ver Postali e Picchetti (2006a) para um panorama sobre as propriedades de alguns processos estocásticos utilizados pra avaliar investimentos em petróleo e gás.
} 
A expressão (8) é uma equação diferencial ordinária. A solução particular é dada por:

$$
v *=(1-R)(1-Y)\left[\frac{(1-\tau) x}{r-\alpha+\phi-\pi}-\frac{1}{r-\pi}\right]
$$

a qual representa o valor fundamental da reserva.

A solução homogênea tem a forma $v_{H}=A x^{\lambda}$. Substituindo em (8), $\lambda$ é a solução da seguinte equação característica:

$$
\frac{1}{2}\left(\sigma_{P}^{2}-2 \rho \sigma_{P} \sigma_{C}+\sigma_{C}^{2}\right) \lambda^{2}+\left[\alpha-\phi-\frac{1}{2}\left(\sigma_{P}^{2}-2 \rho \sigma_{P} \sigma_{C}+\sigma_{C}^{2}\right)\right] \lambda-(r-\pi)=0
$$

A equação (10) admite duas soluções, $\lambda_{1}>1$ e $\lambda_{2}<0$, de modo que a solução homogênea da equação diferencial é:

$$
v H=B_{1} x^{\lambda_{1}}+B_{2} x^{\lambda_{2}}
$$

Assim, a solução geral é dada por $v=v^{*}+v_{H}$. $B_{1}$ e $B_{2}$ são constantes cujos valores são determinados de acordo com as condições de contorno próprias das flexibilidades admitidas no projeto. Assume-se que o produtor pode encerrar a produção, a um custo $E$, sempre que as condições econômicas forem não favoráveis (e.g.: quando o preço cai demais). Neste sentido, a função lucro (4) se torna:

$$
P O=\operatorname{Max}\{-E, \Pi\}
$$

Em que $\Pi$ é definida de acordo com (4). A equação diferencial representando o valor da reserva depende da função lucro. Se a reserva está desenvolvida e a produção em andamento, a solução de (8) é dada por:

$$
v(x)=B_{1} x^{\lambda_{1}}+B_{2} x^{\lambda_{2}}+(1-R)(1-Y)\left[\frac{(1-\tau) x}{r-\alpha+\phi-\pi}-\frac{1}{r-\pi}\right]
$$

A determinação das constantes requer a definição das condições de contorno. Se a reserva estiver em produção, seu valor é dado pela opção de encerramento $^{20}$, de forma que quando $x \rightarrow \infty$, o investidor nunca a exerce. Assim, dado que $\lambda_{1}>0$, deve-se ter $B_{1}=0$.

Em síntese, na presença de opção de saída, o valor unitário da reserva desenvolvida é dado por:

$$
v(x)=B_{2} x^{\lambda_{2}}+(1-R)(1-Y)\left[\frac{(1-\tau) x}{r-\alpha+\phi-\pi}-\frac{1}{r-\pi}\right]
$$

Com vistas a comparar as opções de investir ou esperar, seja $F(P, C, t)$ o valor unitário da reserva não-desenvolvida, também governado pelo preço do recurso e pelo custo unitário operacional, de acordo com o MBG (1) e (2). O valor unitário da reserva não-desenvolvida é uma opção de compra Americana cujo ativo subjacente é a reserva desenvolvida e com preço de exercício igual ao investimento - $I$ - necessário para desenvolvê-la.

${ }^{20}$ Este resultado pressupõe a aditividade do valor, conforme definido por Trigeorgis (1993). 
Pelo Princípio de Bellman ${ }^{21}$ :

$$
r F(P, C, t) d t=E_{0}(d F)
$$

O processo para obtenção da solução segue os mesmos passos que o da reserva desenvolvida, exceto para o componente do tempo. Agora, supõe-se que o investidor mantém em aberto a opção de desenvolver por tempo indefinido, aproximando-se, pois, para uma opção sem vencimento, de forma que $F t=0$. Trata-se de uma aproximação que se encaixa razoavelmente bem na lei do Petróleo brasileira, que estabelece prazos de até nove anos (prorrogáveis por mais cinco) para as concessões de exploração. Conforme salientam Dixit e Pindyck (1994, p. 401), “(...) the critical ratio is not very sensitive to the time to expiration if that time is greater than one or two years. Hence for many such investments in oil reserves, it is a reasonable approximation to ignore the relinquishment requirement altogether, and simply treat the option to develop as perpetual". No presente modelo, isso significa que, para valores razoáveis de $\alpha, r, \sigma_{P}, \sigma_{C}, \rho$ e $\phi$, o incremento de valor na reserva diante de alterações na maturidade, quando esta é superior a cinco anos, é desprezível.

Adotando esta aproximação e utilizando os mesmos resultados de homogeneidade da função valor, tem-se:

$$
\frac{1}{2}\left(\sigma_{P}^{2}-2 \rho \sigma_{P} \sigma_{C}+\sigma_{C}^{2}\right) x^{2} f^{\prime \prime}(x)+(\alpha-\phi) x f^{\prime}(x)-r f(x)=0
$$

A equação (15) admite a seguinte solução analítica:

$$
f(x)=A 1 x l 1+A 2 x l 2
$$

onde $\lambda_{1}>1$ e $\lambda_{2}<0$ são as raízes de uma equação característica polinomial quadrática, sendo $A_{1}$ e $A_{2}$ constantes. Quando $x \rightarrow 0$ é improvável que a opção de desenvolver seja exercida, de forma que $f(0)=0$. Consequentemente, $A 2=0$.

Duas condições de contorno precisam ser satisfeitas: a condição de contato (value-matching) e a condição de suavidade (smooth-pasting), as quais são dadas, respectivamente, por $^{22}$ :

$$
\tilde{F}(P, C)=\tilde{V}(P, C)-I \Rightarrow f(x)=v(x)-I / C
$$

$\mathrm{e}$

$$
f^{\prime}(x)=v^{\prime}(x)
$$

A condição de contato estabelece a regra ótima para o exercício da opção de investir, que consiste na igualdade entre o valor da reserva não-desenvolvida e o valor da desenvolvida subtraído do investimento irreversível. Se $\tilde{F}(P, C)>$ $\tilde{V}(P, C)-I$, a melhor decisão é esperar. Caso contrário, o desenvolvimento imediato representa a estratégia ótima. Portanto, a condição de contato impõe

\footnotetext{
21 A rigor, deveríamos definir $F(V, t)$. No entanto, o processo de difusão de $V$ possui uma expressão muito complicada e a equação diferencial ligando $F$ a $V$ é de difícil solução. Um procedimento alternativo mais simples é definir diretamente o valor da reserva não-desenvolvida como função de $x=P / C$, utilizando-se a solução de $V$ como condição de contorno. Ver Dixit e Pindyck (1994, p.182) para detalhes.

22 Ver Dixit e Pindyck (1994, cap. 4).
} 
Tabela 1: Razões críticas e decisão de investir

\begin{tabular}{lll}
\hline$x \equiv P / C$ & Reserva Não-Desenvolvida & Reserva Desenvolvida \\
\hline$x<x S$ & Esperar & Encerrar \\
$x=x S$ & Esperar & Indiferente entre encerrar e \\
& & operar \\
$x S<x<x E$ & Esperar & Operar \\
$x=x E$ & Indiferente entre & Operar \\
& desenvolver ou não & \\
$x>x E$ & Desenvolver & Operar \\
\hline
\end{tabular}

continuidade em $v$ e $f^{23}$. A condição de suavidade garante a continuidade na inclinação, evitando quebras no ponto ótimo.

A decisão de investir depende da razão crítica $x \equiv P / C$. Sejam $x^{E}$ e $x^{S}$ as razões preço-custo críticas que induzem, respectivamente, o desenvolvimento e o abandono da reserva. A decisão ótima dependerá tanto do valor de $x$ quanto do modo de operação: se a reserva não está desenvolvida, a variável de decisão é $x^{E}$, isto é, a razão crítica que determina o exercício da opção de desenvolver $^{24}$. Por outro lado, se a reserva está desenvolvida, a decisão ótima é relativa à saída, a qual é ótima quando $x \leq x^{S}$.

A Tabela 1 sintetiza as decisões ótimas de acordo com o valor de $x$. O valorlimite $x^{E}$ indica a razão preço-custo crítica que torna ótimo o desenvolvimento da jazida, mas a opção de saída só é ótima quando $x \leq x^{S}$. Há, portanto, um fenômeno de histerese (Dixit, 1992) e, quanto maior a distância entre $x^{S}$ e $x^{E}$, maior a distorção sobre a decisão de investir.

A otimalidade da decisão de investimento depende dos valores relativos das reservas desenvolvida e não-desenvolvida. As razões $x^{E}$ e $x^{S}$ são determinadas pelas condições de contorno (value-matching e smooth pasting) em cada modo de operação. Primeiramente, considere a firma diante da decisão entre desenvolver ou não uma jazida. Substituindo (13) e (16) em (17) e (18) para $x \leq x^{E}$, obtém-se:

$$
\begin{gathered}
-A_{1}\left(x^{E}\right)^{\lambda_{1}}+B_{2}\left(x^{E}\right)^{\lambda_{2}}+(1-R)(1-Y)\left[\frac{(1-\tau) x^{E}}{r-\alpha+\phi-\pi}-\frac{1}{r-\pi}\right]-i=0 \\
-A_{1} \lambda_{1}\left(x^{E}\right)^{\lambda_{1}-1}+B_{2} \lambda_{2}\left(x^{E}\right)^{\lambda_{2}-1}+\frac{(1-R)(1-Y)(1-\tau)}{r-\alpha+\phi-\pi}=0
\end{gathered}
$$
reais).

em que $i=I / C$, isto é, a razão investimento-custo de operação (em valores

Além disso, uma firma em operação deve considerar a decisão de encerrar a produção se o cenário econômico piorar, o que significa que a razão preçocusto deve cair abaixo de $x^{S}$. As condições de contorno se tornam:

$$
v\left(x^{S}\right)=f\left(x^{S}\right)-\varepsilon
$$

\footnotetext{
${ }^{23} f(x)$ também pode ser interpretado como o custo de oportunidade do investimento (Dixit e Pindyck 1994), que consiste em esperar por mais informações antes de investir.

24 Assume-se que o investidor não desenvolve uma jazida para mantê-la inoperante.
} 


$$
v^{\prime}\left(x^{S}\right)=f^{\prime}\left(x^{S}\right)
$$

Na qual $\varepsilon=E / C$, sendo $E$ o custo de saída. Estas duas condições podem ser interpretadas de forma análoga que () e (), referentes à opção de investir: no caso de decisão de encerrar, $x^{S}$ deve tornar o produtor indiferente entre o valor da reserva desenvolvida e o valor da reserva inoperante (se houver), líquida dos custos de saída. Seguindo o mesmo procedimento anterior, tem-se:

$$
\begin{gathered}
-A_{1}\left(x^{S}\right)^{\lambda_{1}}+B_{2}\left(x^{S}\right)^{\lambda_{2}}+(1-R)(1-Y)\left[\frac{(1-\tau) x^{S}}{r-\alpha+\phi-\pi}-\frac{1}{r-\pi}\right]-\varepsilon=0 \\
-A_{1} \lambda_{1}\left(x^{S}\right)^{\lambda_{1}-1}+B_{2} \lambda_{2}\left(x^{S}\right)^{\lambda_{2}-1}+\frac{(1-R)(1-Y)(1-\tau)}{r-\alpha+\phi-\pi}=0
\end{gathered}
$$

As equações (19), (20), (21) e (22) constituem um sistema não-linear com quatro equações e quatro incógnitas: $A_{1}, B_{2}, x^{E}$ e $x^{S}$. Este sistema não apresenta solução analítica, requerendo métodos numéricos ${ }^{25}$. Como $A_{1}$ e $B_{2}$ são valores de opções, eles devem ser positivos.

A seção seguinte apresenta os dados utilizados para calibrar o modelo assim como seus resultados.

\section{Resultados.}

\subsection{Impacto sobre o Investimento.}

O exercício de simulação visa avaliar o impacto de diferentes desenhos de alíquotas de royalties e Participações Especiais sobre as razões críticas $x^{E} \mathrm{e}$ $x^{S}$, e sobre o valor da reserva. A distorção na decisão de investir é medida pela diferença entre as razões críticas sob determinada estrutura de alíquotas e tais valores na ausência de cargas fiscais. A Tabela 2 resume os parâmetros de referência para calibrar o modelo.

Assume-se que a taxa de desconto seja de $10 \%$ ao ano; tanto o drift quanto o desvio padrão do preço do petróleo foram estimados a partir de dados anuais WTI Crude Oil, de 1986 a $2005^{26}$. Supõe-se, ainda, que o desvio padrão dos custos operacionais seja a metade do desvio padrão do preço, já que o produtor possui mais informações acerca de seu processo produtivo do que sobre o conjunto de fatores que afeta o preço do petróleo.

A variável $i$ é a razão investimento-custo para desenvolver um barril de petróleo da reserva. Quanto maior $i$, menor a qualidade do recurso na jazida $\left(\right.$ grade $\left.^{27}\right)$. Assume-se um valor de referência unitário para esta variável, assim como para a razão custo de saída-custo operacional, e.

O coeficiente de correlação instantânea entre o preço e o custo, $\rho$, também é um parâmetro relevante. Ele foi calibrado considerando a existência de uma alta correlação positiva entre preço e custos de operação (Adelman et Al.,

\footnotetext{
${ }^{25}$ Utilizamos o de Newton-Raphson.

${ }^{26}$ Fonte: EIA - Departamento de Energia EUA.

${ }^{27}$ Em geral, o grade é um atributo dos minérios. De acordo com Costa Lima e Suslick (2006), trata-se da razão entre a massa útil de minério e a massa de rocha. Para recursos fluidos, o grade é uma medida de qualidade. Coeteris paribus, um grade menor indica um maior custo médio de extração.
} 
Tabela 2: Valores de referência (iniciais) para os parâmetros

\begin{tabular}{lll}
\hline Parâmetro & Valor & Fonte \\
\hline$P_{0}$ & $\$ 90$ & (assumido) \\
$C_{0}$-alta qualidade & $\$ 3,70$ & Blake e Roberts (2006) \\
$C_{0}$ - baixa qualidade & $\$ 5,08$ & \\
Estoque inicial - alta qua- & $300 \times 10^{6}$ barris & Blake e Roberts (2006) \\
lidade & & Blake e Roberts (2006) \\
Estoque inicial - baixa & $75 \times 10^{6}$ barris & \\
qualidade & & Blake e Roberts (2006) \\
$r$ & $10 \%$ & (assumido) \\
$\pi$ & $3 \%$ & (assumido) \\
$\alpha$ & $6,2 \%$ & WTI Crude Oil - 1986- \\
& & 2005 \\
$\phi$ & $10 \%$ & Dixit e Pindyck (1994) \\
$\sigma_{P}$ & $21,18 \%$ & WTI Crude Oil - 1986- \\
& & 2005 \\
$\sigma_{C}$ & $10 \%$ & (assumido) \\
$\rho$ & $+0,9$ & Adelman et Al. (1989) \\
$\iota \equiv I / C$ & 1 & (assumido) \\
$\varepsilon \equiv E / C$ & 1 & (assumido) \\
$Y=I R P J+C S L L$ & $34 \%$ & Legislação brasileira \\
$\tau t$ & $10 \%$ & Lei do Petróleo (9478/97) \\
$R$ & $0 \%$ & Decreto 2705/98 (mínimo) \\
\hline
\end{tabular}

1989), já que quando os preços estão elevados, produtores marginais entram no mercado, elevando a demanda por insumos e, consequentemente, pressionando seus preços. As razões críticas $x^{E}$ e $x^{S}$ foram calculadas assumindo-se $\rho=0,9$ (M.A. et al. 1989, Dias 1996).

Finalmente, as alíquotas de royalties e de Participações Especiais foram definidas de acordo com os valores previstos na Lei do Petróleo, enquanto os demais tributos legais foram definidos de acordo com a legislação. $Y$ foi estabelecido como igual a $34 \%$, que representa a soma das alíquotas do Imposto de Renda Pessoa Jurídica (IRPJ) com a Contribuição Social sobre o Lucro Líquido (CSLL). Os royalties podem variar de $5 \%$ a $10 \%$ da receita bruta de produção, dependendo das condições de risco do campo em questão. No entanto, a maior parte dos projetos é tributada com a alíquota máxima de $10 \%$, a qual foi estabelecida como parâmetro inicial nas simulações. As Participações Especiais, por sua vez, apresentam alíquotas progressivas que variam entre 0 e $40 \%$. Como referência inicial, assumiu-se uma alíquota de $0 \%$ para esta modalidade. Na prática, a apuração das Participações Especiais envolve uma regra complicada, que depende do volume do campo, da sua idade e da profundidade de extração. Apenas os projetos de alta produção devem recolher tal tributo, de forma que um investimento de tamanho médio costuma ser isento. Aqui, consideramos que as Participações Especiais podem ser aplicadas a todos os projetos, ou seja, simula-se a generalização de sua utilização para todos os projetos de produção. 
Tabela 3: Resultados de referência $-x \equiv P / C$

\begin{tabular}{lcc}
\hline Modelo & $x^{E}$ & $x^{S}$ \\
\hline Valor Presente Líquido & 1,896 & - \\
Opção real - sem opção de abandono & 2,201 & - \\
Opção real - com opção de abandono sem custos & 1,689 & 0,958 \\
Opção real - com opção de abandono com custos $(e=1)$ & 1,845 & 0,849 \\
\hline
\end{tabular}

Calibrando-se o modelo com os parâmetros da Tabela 2, obtêm-se as razões de referência apresentadas na Tabela 3. A fim de investigar o impacto da estrutura fiscal sobre a decisão de investir, avaliam-se os efeitos de diversas combinações de alíquotas de royalties e Participações Especiais $(\tau, R)$ sobre as razões críticas ${ }^{28} x^{E}$ e $x^{S}$.

A razão crítica para o desenvolvimento cresce em relação à análise de VPL quando a opção de investir é incorporada, já que a análise de opções reais permite avaliar o efeito da irreversibilidade. No entanto, quando a opção de abandono está presente, esta razão se reduz e o investimento se torna mais atrativo. Este resultado está de acordo com a constatação de que flexibilidades gerenciais adicionam valor ao projeto, facilitando a decisão de investir (Kulatilaka, 1995). Quando se introduzem custos de abandono, a razão crítica para investimento $\left(x^{E}\right)$ cresce enquanto a razão para saída $\left(x^{S}\right)$ se reduz, gerando uma histerese mais acentuada.

A Tabela 4 apresenta as razões críticas para desenvolvimento $\left(x^{E}\right)$ na ausência de opção de abandono, para algumas combinações de alíquotas $(\tau, R)$. Neste caso, os investidores devem decidir por um investimento irreversível ${ }^{29}$. Os valores entre parênteses indicam o grau de distorção, isto é, a diferença percentual entre $x^{E}$ sob a combinação de alíquotas considerada e esta razão na ausência de impostos ${ }^{30}$. Na ausência de opção de saída, os royalties produzem uma distorção maior sobre a decisão de investir do que as Participações Especiais, confirmando resultados tradicionais da literatura sobre taxação de recursos minerais, baseada em $V P L$.

Na presença de opção de abandono, as conclusões sobre distorção se alteram. Agora, as Participações Especiais são capazes de afetar mais fortemente o investimento, como se pode observar na Tabela 5. Por exemplo, uma estrutura de alíquotas $(\tau, \mathrm{R})=(0 ; 40 \%)$ produz uma distorção levemente maior do que a aplicação de uma alíquota uniforme de royalties $(\tau, R)=(10 \%, 0)$ no que se refere á decisão de desenvolver (contida em $x^{E}$ ). Todavia, as Participações Especiais contribuem para reduzir $x^{S}$, isto é, a decisão de abandono se torna menos provável. Além disso, enquanto a alíquota de royalty $(\tau)$ e $x^{S}$ variam na mesma direção, um aumento em $R$ reduz a razão crítica de saída ${ }^{31}$. Portanto, as Participações Especiais contribuem para aumentar a faixa de histerese.

Com relação à distorção no valor da reserva, a Figura 1 mostra a relação

\footnotetext{
28 Os cálculos foram realizados no Matlab 7.0.

${ }^{29}$ De acordo com a Lei do Petróleo, o concessionário não pode abandonar ou transferir a concessão sem autorização da ANP.

${ }^{30} \mathrm{O}$ grau de distorção é dado por $100\left(x^{E}-x^{*}\right) / x^{*}$, onde $x^{*}$ é a razão crítica na ausência de impostos, isto é, $\tau=0, R=0$. Mudanças nos valores críticos $x^{E}$ são equivalentes a variações no valor da reserva desenvolvida. Por exemplo, um aumento da alíquota de royalties ou de participações especiais reduz o valor da reserva desenvolvida para o produtor, o que dificulta o investimento,
} 
Tabela 4: Razões críticas na ausência de opção de abandono

\begin{tabular}{|c|c|c|c|}
\hline \multirow[b]{2}{*}{$R(\%)$} & \multicolumn{3}{|c|}{$\tau(\%)$} \\
\hline & 0 & 5 & 10 \\
\hline 0 & $\underset{*}{1,981}$ & $\begin{array}{l}2,086 \\
(5,26 \%)\end{array}$ & $\begin{array}{c}2,202 \\
(11,11 \%)\end{array}$ \\
\hline 10 & $\begin{array}{l}2,002 \\
(1,06 \%)\end{array}$ & $\begin{array}{l}2,108 \\
(6,38 \%)\end{array}$ & $\begin{array}{c}2,225 \\
(12,29 \%)\end{array}$ \\
\hline 20 & $\begin{array}{l}2,029 \\
(2,39 \%)\end{array}$ & $\begin{array}{l}2,136 \\
(7,78 \%)\end{array}$ & $\begin{array}{c}2,254 \\
(13,77 \%)\end{array}$ \\
\hline 30 & $\begin{array}{l}2,063 \\
(4,11 \%)\end{array}$ & $\begin{array}{l}2,171 \\
(9,58 \%)\end{array}$ & $\begin{array}{c}2,292 \\
(15,67 \%)\end{array}$ \\
\hline 40 & $\begin{array}{l}2,108 \\
(6,39 \%)\end{array}$ & $\begin{array}{c}2,219 \\
(11,99 \%)\end{array}$ & $\begin{array}{c}2,342 \\
(18,21 \%)\end{array}$ \\
\hline
\end{tabular}

Valores de $x_{E}$ representados acima e valores de $\Delta x_{E} / x_{E}$ representados abaixo e entre parênteses.

Tabela 5: Razões críticas na presença de opção de abandono

\begin{tabular}{|c|c|c|c|c|c|c|}
\hline \multirow{3}{*}{$R(\%)$} & \multicolumn{6}{|c|}{$\tau(\%)$} \\
\hline & \multicolumn{2}{|c|}{0} & \multicolumn{2}{|c|}{5} & \multicolumn{2}{|c|}{10} \\
\hline & $x^{E}$ & $x^{S}$ & $x^{E}$ & $x^{S}$ & $x^{E}$ & $x^{S}$ \\
\hline 0 & 1,66 & 0,764 & $\begin{array}{l}1,747 \\
(5,26 \%)\end{array}$ & $\begin{array}{l}0,805 \\
(5,26 \%)\end{array}$ & $\begin{array}{c}1,845 \\
(11,11 \%)\end{array}$ & $\begin{array}{c}0,849 \\
(11,11 \%)\end{array}$ \\
\hline 10 & $\begin{array}{l}1,699 \\
(2,38 \%)\end{array}$ & $\begin{array}{c}0,754 \\
(-1,38 \%)\end{array}$ & $\begin{array}{l}1,789 \\
(7,76 \%)\end{array}$ & $\begin{array}{l}0,794 \\
(3,80 \%)\end{array}$ & $\begin{array}{c}1,888 \\
(13,75 \%)\end{array}$ & $\begin{array}{l}0,838 \\
(9,57 \%)\end{array}$ \\
\hline 20 & $\begin{array}{l}1,747 \\
(5,23 \%)\end{array}$ & $\begin{array}{c}0,741 \\
(-3,10 \%)\end{array}$ & $\begin{array}{c}1,839 \\
(10,77 \%)\end{array}$ & $\begin{array}{c}0,78 \\
(2,00 \%)\end{array}$ & $\begin{array}{c}1,941 \\
(16,92 \%)\end{array}$ & $\begin{array}{l}0,823 \\
(7,67 \%)\end{array}$ \\
\hline 30 & $\begin{array}{l}1,805 \\
(8,74 \%)\end{array}$ & $\begin{array}{c}0,724 \\
(-5,26 \%)\end{array}$ & $\begin{array}{c}1,9 \\
(14,46 \%)\end{array}$ & $\begin{array}{c}0,762 \\
(-0,28 \%)\end{array}$ & $\begin{array}{c}2,006 \\
(20,82 \%)\end{array}$ & $\begin{array}{l}0,805 \\
(5,25 \%)\end{array}$ \\
\hline 40 & $\begin{array}{c}1,879 \\
(13,18 \%)\end{array}$ & $\begin{array}{c}0,702 \\
(-8,13 \%)\end{array}$ & $\begin{array}{c}1,978 \\
(19,13 \%)\end{array}$ & $\begin{array}{c}0,739 \\
(-3,30 \%)\end{array}$ & $\begin{array}{c}2,088 \\
(25,75 \%)\end{array}$ & $\begin{array}{c}0,78 \\
(2,07 \%)\end{array}$ \\
\hline
\end{tabular}

Valores de $x^{E}$ e $x^{S}$ representados acima e valores de $\Delta x^{E} / x^{E}$ e de $\Delta x^{S} / x^{S}$ representados abaixo e entre parênteses. 


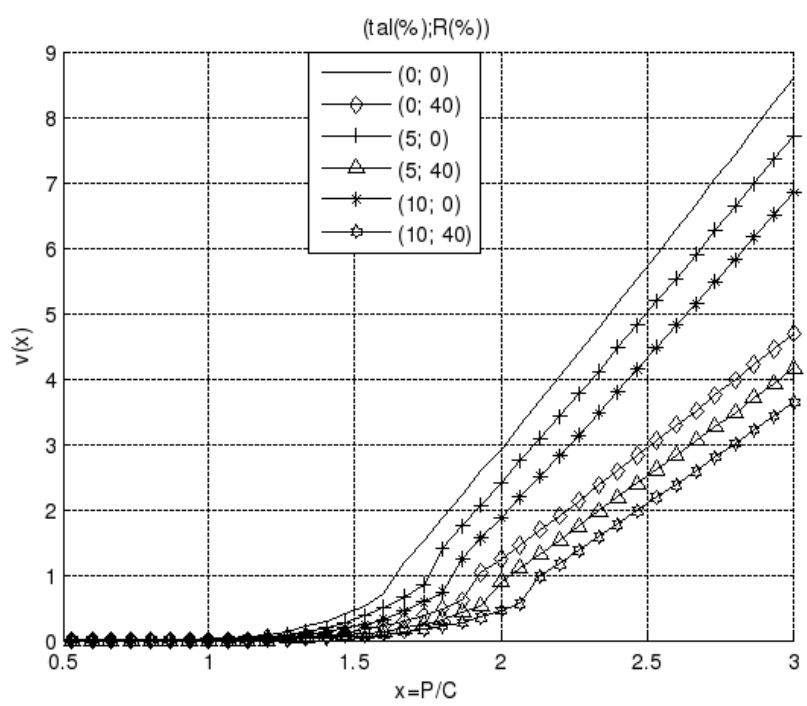

Figura 1: Valor unitário da reserva desenvolvida $-v(x)$

entre o valor unitário da reserva desenvolvida, $v(x)$ como função da razão $x$, para algumas combinações selecionadas de alíquotas $(\tau, R)^{32}$. Conforme indicado na legenda, a linha cheia indica o valor unitário da reserva, na ausência de impostos. Quanto maior a distância da curva de valor para cada combinação de alíquotas em relação a esta original, maior a distorção provocada pela estrutura tributária. Como se observa, alíquotas elevadas de Participação Especial causam impactos mais nocivos sobre o investimento, já que provocam maiores deslocamentos verticais sobre a curva de valor.

Duas conclusões interessantes podem ser extraídas. Em primeiro lugar, existem combinações de alíquotas de royalties e Participações Especiais menos deletérias do que uma alíquota única de $10 \%$. Por exemplo, uma combinação de $(\tau, R)=(5 \% ; 10 \%)$ torna o investidor menos resistente em desenvolver a reserva o que uma alíquota única de $10 \%$ de royalties, como a carga tributária de um projeto fiscal típico no Brasil. Além disso, ceteris paribus, sob uma combinação $(5 \% ; 20 \%)$ o investidor está menos propenso a abandonar o investimento ( $x^{S}$ é menor). Entretanto, um aumento demasiado na alíquota de Participação Especial (e.g.: acima de 30\%) resulta em distorções maiores sobre as razões críticas, quando a opção de encerrar a produção está presente. Além disso, conforme o preço do petróleo se eleva (e consequentemente a razão $x$ ), a participação especial distorce mais fortemente o investimento (na Figura 1, note que a distância entre as curvas com e sem $R$ aumenta conforme $x$ cresce).

Esta é a segunda conclusão importante: um aumento das cargas fiscais com base em Participações Especiais pode piorar a disposição em investir quando

de modo que há um aumento na razão crítica de entrada.

${ }^{31}$ Este resultado é compatível com um perfil de divisão de riscos de um imposto sobre a renda do recurso, segundo o qual esta modalidade tributária reduziria tanto o valor do investimento quanto seu desvio padrão (Mayo 1979). Entretanto, esta não é uma explicação factível aqui, tendo em vista que o modelo pressupõe neutralidade ao risco.

32 A legenda $(\tau, R)$ indica a combinação de alíquotas. Exemplo $(5,40)$ significa royalties de $5 \%$ e participação especial de $40 \%$. 


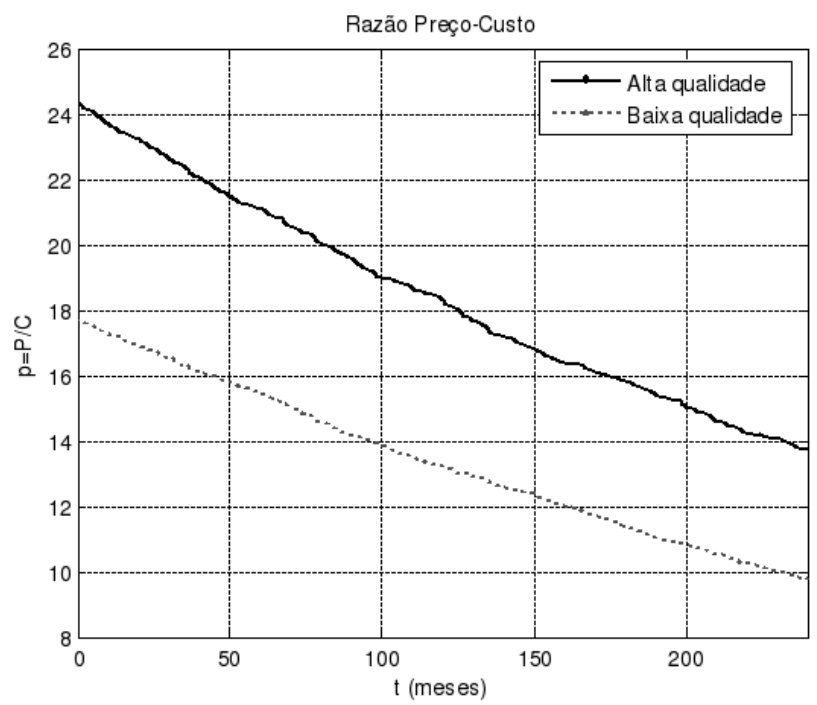

Figura 2: $x=P / C$ - Trajetória esperada (amostra 5000)

o modelo assume presença de opção de saída, mesmo na situação em que o investidor é neutro ao risco. Este resultado não está de acordo com a abordagem tradicional (VPL) de taxação de recursos minerais, na qual os royalties causam impacto mais deletério sobre a disposição de investir do que uma modalidade baseada na renda do recurso. Desta forma, as recentes discussões sobre alterações na estrutura de benefícios governamentais com vistas a extrair maiores rendas nas recém descobertas jazidas do pré-sal, podem afugentar futuros investimentos, se as novas regras forem estendidas às demais concessões.

\subsection{Receitas esperadas.}

A distorção sobre o investimento não deve ser a única variável a orientar a decisão de escolher as alíquotas fiscais, já que também é necessário avaliar o potencial de arrecadação. A apropriação de rendas pelas autoridades governamentais, por sua vez, depende da trajetória esperada dos preços e dos custos de operação.

A fim de se avaliar o potencial arrecadatório de cada estrutura de alíquotas, desenvolveu-se um exercício de Monte Carlo com vistas a simular as trajetórias de preço e custo para os próximos 20 anos. O experimento foi calibrado com os dados da Tabela 2, com uma amostra de 5000 replicações (isto é, foram geradas cinco mil possíveis trajetórias para $P$ e $C$ ). A Figura 2 ilustra a correspondente trajetória esperada para $x=P / C$, tomando como base um preço inicial de $\$ 90$ o barril de petróleo. Supõe-se, também, uma taxa de decaimento anual exógena $\mathrm{f}=10 \%{ }^{33}$, isto é, se $S_{0}$ é o estoque inicial, então o estoque no instante $\tau$ é dado por $S t=S 0(1-f) t$. A Tabela 6 relata as receitas esperadas (parcela do governo no valor da reserva), em valor presente, de acordo com a combinação de alíquotas escolhida, para uma reserva de 300 milhões de bar-

\footnotetext{
${ }^{33}$ Ver nota de rodapé 15 e Dixit \& Pindyck (1994, cap. 6). Esta taxa corresponde a uma meia vida de aproximadamente 7 anos.
} 
Tabela 6: Valor presente esperado da receita do Governo, em milhões de dólares (jazida de alta qualidade 300 milhões de barris).

\begin{tabular}{rcccc}
\hline & \multicolumn{3}{c}{$\tau(\%)$} \\
\cline { 3 - 5 }$R(\%)$ & & 0 & 5 & 10 \\
\cline { 1 - 2 } \cline { 3 - 5 } 10 & & 0 & 119,54 & 239,09 \\
20 & & 302,18 & 405,95 & 509,72 \\
30 & & 453,27 & 549,15 & 645,03 \\
40 & & 604,36 & 692,35 & 780,34 \\
\hline
\end{tabular}

Tabela 7: Valor presente esperado da receita do Governo, em milhões de dólares (jazida de baixa qualidade 75 milhões de barris).

\begin{tabular}{|c|c|c|c|}
\hline \multirow[b]{2}{*}{$R(\%)$} & \multicolumn{3}{|c|}{$\tau(\%)$} \\
\hline & 0 & 5 & 10 \\
\hline 10 & 37,31 & 65,34 & 93,38 \\
\hline 20 & 74,62 & 100,67 & 126,73 \\
\hline 30 & 111,94 & 136,01 & 160,08 \\
\hline 40 & 149,25 & 171,34 & 193,43 \\
\hline
\end{tabular}

ris (alta qualidade), correspondente a um custo operacional inicial de $\$ 3,70$ (Blake e Roberts 2006) ${ }^{34}$. A Tabela 7 apresenta as mesmas estimativas para uma reserva de baixa qualidade, correspondente a 75 milhões de barris e um custo operacional inicial de $\$ 5,08^{35}$.

Os resultados sugerem que um sistema fiscal baseado em Participações Especiais é mais efetivo em extrair uma porção maior da renda do recurso, sobretudo em depósitos de alta qualidade. Uma combinação de $(\tau, R)=(5 \%, 20 \%)$, por exemplo, é capaz de gerar mais arrecadação ao mesmo tempo em que distorce menos a decisão de investir (vide tabelas 4 e 5) do que uma alíquota única de $10 \%$ de royalties. As figuras 3 e 4 mostram a arrecadação de recursos do petróleo para jazidas de 300 milhões e de 75 milhões de barris, respectiva-

\footnotetext{
${ }^{34}$ Com base em um estudo do Banco Mundial, Blake e Roberts (2006) apresentam dados sobre a relação entre o tamanho de uma jazida e o custo de produção por barril. Um campo de 300 milhões de barris apresenta um custo operacional estimado em $\$ 3,70$ enquanto um campo de 75 milhões apresenta um custo de $\$ 5,08$. Com base em Lund (1992), eles assumem uma função esforço que estabelece uma relação entre o investimento em exploração e o tamanho das reservas recuperáveis.

${ }^{35}$ É importante salientar que todas as estimativas apresentam um custo fixo normalizado para zero. Assim, tais valores não constituem uma projeção precisa de um projeto de investimento em petróleo. Trata-se apenas de comparar as magnitudes das arrecadações. Além disso, ambos os resultados consideram as razões críticas de saída reportadas na Tabela 5, embora elas não impactem nas estimativas, tendo em vista a magnitude atual do preço.
} 


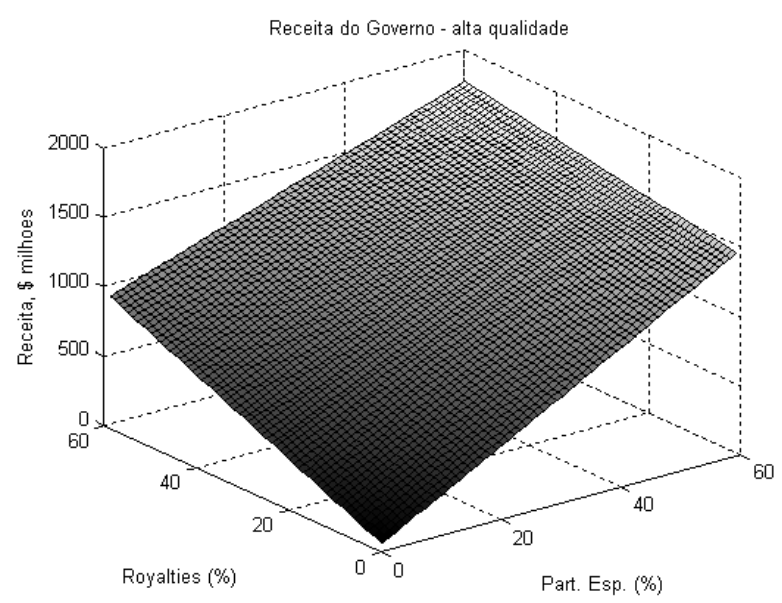

Figura 3: Parcela do governo nas rendas do petróleo, como função das alíquotas de royalties e participações especiais - jazida de alta qualidade

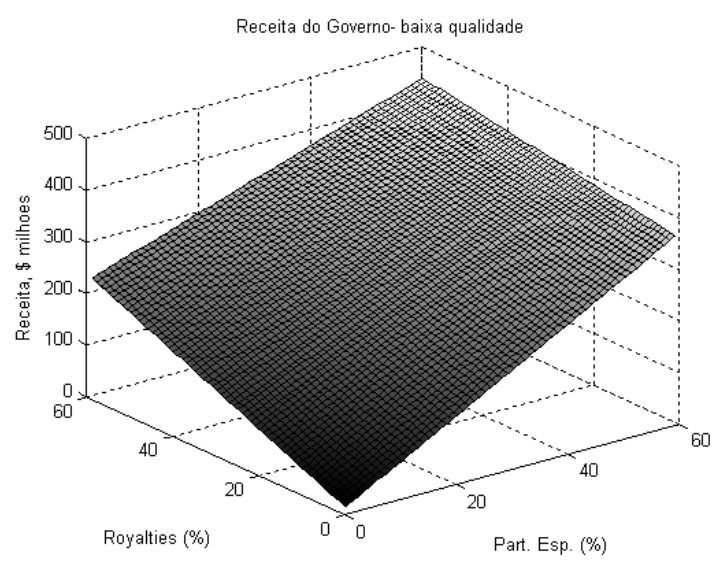

Figura 4: Parcela do governo nas rendas do petróleo, como função das alíquotas de royalties e participações especiais - jazida de baixa qualidade

mente, variando-se as alíquotas de royalties e de participações especiais nos eixos $x$ e $y$. Confirma-se, pois, o maior potencial arrecadatório de um imposto sobre a renda: na medida em que se avançam em direção a maiores alíquotas de participações especiais, maior a arrecadação do governo para os dois tipos de reserva.

As estimativas sugerem que um sistema baseado em Participações Especiais pode aumentar a participação do governo na renda do recurso, mas a custa de uma distorção maior na decisão de investir. Em particular, uma ampliação da Participação Especial (como cogitado nas reservas do pré-sal) pode aumentar a razão crítica de entrada e reduzir a razão crítica para o abandono, 
reduzindo a predisposição ao investimento, além de corroer o valor unitário da reserva.

\section{Conclusão}

O objetivo deste artigo foi avaliar o efeito distorcivo do regime fiscal brasileiro do setor de petróleo e gás - chamados Benefícios Governamentais - sobre a decisão de investir em desenvolvimento de reservas, à luz de uma análise de opções reais, que permite incorporar as flexibilidades gerenciais no valor do projeto.

A literatura sobre taxação de recursos minerais, predominantemente baseada na análise de Valor Presente Líquido, mostra que tributos baseados na receita (como os royalties) são capazes de introduzir mais distorções do que o imposto sobre a renda do recurso. A razão disso decorre do fato de que tais impostos podem alterar a ordem de lucratividade dos potenciais projetos, assim como tornar negativo um VPL esperado que, de outra forma, seria positivo. Embora esta propriedade distorciva dos impostos sobre receita seja válida para os investimentos em quaisquer setores, ela é mais sensível no setor extrativo, diante das peculiaridades do risco inerente a esta atividade.

Este artigo buscou contribuir com a discussão sobre a relação entre o regime fiscal e a decisão de investimentos, a partir de uma análise de opções reais, na qual o valor das flexibilidades é incorporado ao projeto. Em particular, buscou-se investigar o efeito de uma ampliação das Participações Especiais como mecanismo de extração da renda petrolífera, de acordo com as atuais discussões sobre o pré-sal (atualmente no Brasil, a estrutura é fortemente concentrada em royalties). As conclusões são diferentes dependendo do tipo de flexibilidade admitida: a) na ausência de opção de encerrar, o investimento seria facilitado (Tabela 4); b) na presença de opção de encerrar, a decisão de investir seria potencialmente prejudicada (Tabela 5), dependendo da combinação de alíquotas escolhida. Desta forma, as simulações mostram um potencial trade-off: um sistema concentrado em Participações Especiais resulta em receitas esperadas maiores do que uma estrutura concentrada em royalties (como usual no Brasil). Daí a proposta do governo em ampliá-las para os novos campos. No entanto, os investidores podem se tornar mais resistentes ao investimento no desenvolvimento, sobretudo quando a análise leva em consideração o valor da opção de encerramento da produção.

Este trabalho possui limitações e diversas extensões são possíveis: processos estocásticos mais complexos (e talvez mais aderentes à realidade) para descrever as variáveis de estado que governam o valor da reserva (e.g.: reversão à média, saltos com reversão à média, etc.). Além disso, empreendeu-se uma avaliação assumindo que o investidor é neutro ao risco e a taxa de desconto foi tomada como dada, mas poder-se-ia introduzir aversão ao risco (via CAPM, por exemplo). Finalmente, outras flexibilidades gerenciais podem ser agregadas além da opção de investir e da opção de abandono.

Mesmo assim, esta análise é suficiente para mostrar como um imposto baseado na renda do recurso, apesar de elevar a receita esperada do governo, pode introduzir distorções adicionais na decisão de investimento. Assim, as discussões sobre alterações no regime tributário previsto na Lei do Petróleo, destinadas a abocanhar parcela maior da renda do recurso dos novos campos do pré-sal, devem ser conduzidas com cautela, tendo em vista seus potenciais 
efeitos deletérios sobre a disposição de investir.

\section{Referências Bibliográficas}

A.B. Abel, A. Dixit, J.C. Eberly, e R. Pindyck. Options, the value of capital, and investment. The Quartely Journal of Economics, 111(3):753-777, 1996.

A. J. Blake e M.C. Roberts. .comparing petroleum fiscal regimes under oil price uncertainty. Resources Policy, 31(0):95-105, 2006.

P.G Bradley. On the use of modern asset pricing theory for comparing alternative royalty systems for petroleum development projects. Energy Journal, 19(1):47-81, 1998.

M.J. Brennan e E. Schwartz. Evaluating natural resource investments. Journal of Business, 58(2):135-157, 1985.

E.C. Brown. Business income, taxation, and investment incentives. In L.A. et al. (Eds.) Metzler, editor, Income, Employment, and Public Policy: Essays in Honor of Alvin H. Hansen. Norton, 1948.

H.F. Campbell e R.K. Lindner. Mineral exploration and the neutrality of rent royalties. Economic Record, 61(172):445-449, 1985a.

H.F. Campbell e R.K. Lindner. A model of mineral exploration and resource taxation. Economic Journal, 95(377):146-160, 1985b.

G. Costa Lima e S. Suslick. Estimating the volatility of mining projects considering price and operating cost uncertainties. Resources Policy, 31(0):86-94, 2006.

M.A.G. Dias. Investimento sob incerteza na exploração e produção de petróleo. Master's thesis, PUC, Rio de Janeiro, 1996.

A. Dixit. Entry and exit decisions under uncertainty. Journal of Political Economy, 97(3):620-638, 1989.

A. K. Dixit e R. S. Pindyck. Investment under Uncertainty. Princeton University Press, Nova Jersey., 1994.

R. Fraser. On the neutrality of the resource rent tax. Economic Record, 69(204): 56-60, 1993.

R. Fraser. An analysis of the relationship between uncertainty-reducing exploration and resource taxation. Resources Policy, 24(4):199-205, 1998.

R. Garnaut e A. Clunies Ross. Taxation of Mineral Rents. Oxford University Press, New York, 1983.

D. Lund. Petroleum taxation under uncertainty: contingent claims analysis with an application to norway. Energy Economics, 14(0):23-31, 1992.

M.A., Koehn M.F, e Silva H. Adelman. The valuation of oil reserves. In SPE Hydrocarbon Economics and evaluation symposium, 1989.

S. Majd e R. Pindyck. Time to build, option value and investment decisions. Journal of Financial Economics, 18(0):7-27, 1987. 
G. B. Martins e M. E. Silva. A real option model with uncertain, sequential investment and with time to build. Revista Brasileira de Finanças, 3(2):0, 2005.

W. Mayo. Rent royalties. Economic Journal, 55(150):202-213, 1979.

R. L. McDonald e D.R. Siegel. Investment and the valuation of firms when there is an option to shut down. International Economic Review, 26(2):331349, 1985.

S.C. Myers e S. Majd. Abandonment value and project life. Advances in Futures and Options Research, 4(0):1-21, 1990.

P. Osmundsen. Dynamic taxation of non-renewable natural resources under asymmetric information about reserves. Canadian Journal of Economics, 31 (4):933-951, 1998.

J.L Paddock, D.R. Siegel, e J.L. Smith. Option valuation of claims on real assets: the case of offshore petroleum leases. The Quartely Journal of Economics, 103(0):479-508, 1988.

R.S. Pindyck. Irreversible investment, capacity choice, and the value of the firm. American Economic Review, 78(5):969-985, 1988.

F.A.S. Postali. Renda Mineral, Divisão de Riscos e Benefícios Governamentais na Exploração de Petróleo no Brasil. BNDES, Rio de Janeiro, 2002.

F.A.S. Postali e P. Picchetti. Irreversibilidade dos investimentos e valor da opção de encerrar a extração de petróleo. Pesquisa e Planejamento Econômico, 36(2):289-318, 2006.

E. S. Schwartz e L. (orgs.) Trigeorgis. Real Options and Investment under uncertainty: classical readings and recent contributions. MIT, Cambridge, 2001.

L. Trigeorgis. The nature of option interaction and the valuation of investments with multiple real options. Journal of Financial and Quantitative Analysis, 28(1):0, 1993.

L. Zhang. Neutrality and efficiency of petroleum revenue tax: A theoretical assessment. Economic Journal, 107(443):1106-1120, 1997. 